\title{
Mitral valve dysplasia syndrome: A unique form of left-sided heart disease
}

\author{
Lindsay S. Rogers, MD, ${ }^{a}$ Amy L. Peterson, MD, ${ }^{\mathrm{a}}{ }^{\mathrm{J}}$. William Gaynor, MD, ${ }^{\mathrm{b}}$ Jonathan J. Rome, MD, ${ }^{\mathrm{a}}$ \\ Paul M. Weinberg, MD, ${ }^{a}$ and Jack Rychik, $\mathrm{MD}^{\mathrm{a}}$
}

Background: Mitral valve dysplasia syndrome is a unique form of left-sided heart disease characterized by aor-
tic outflow hypoplasia, dilated left ventricle, dysplastic/incompetent mitral valve, and a restrictive/intact atrial
septum. Patients with this constellation of abnormalities have been managed in a variety of ways with overall
poor outcomes.

Methods: We performed a retrospective review of all patients with mitral valve dysplasia syndrome to identify fetal echocardiographic markers predictive of outcomes.

Results: Mitral valve dysplasia syndrome was identified in 10 fetuses. Fetal left heart dilation and abnormal pulmonary venous flow were associated with increased mortality. Seven fetuses had abnormal pulmonary venous Doppler patterns; 3 had a unique "double-reversal" flow pattern. Severe fetal left heart dilation (left heart/right heart area ratio $>1.5$ ) was present in 5. Prenatal intervention was performed on 3 fetuses: balloon aortic valvuloplasty $(\mathrm{n}=2)$ and balloon atrial septostomy $(\mathrm{n}=1)$. Of the 3 , one died in utero and neither survivor underwent a 2-ventricle repair. Five patients required an immediate postnatal intervention to open the atrial septum. The overall mortality was $50 \%$.

Conclusions: Mitral valve dysplasia syndrome is a unique form of congenital heart disease with severe aortic stenosis but normal or enlarged left ventricle secondary to primary mitral valve disease. Increased left heart size and pulmonary vein Doppler patterns are predictive of postnatal outcome. Despite the presence of a dilated left ventricle, postnatal management with staged single ventricle palliation may be the most effective strategy. (J Thorac Cardiovasc Surg 2011;142:1381-7)

Critical left-sided obstructive heart disease can manifest within a wide spectrum of anatomic variability. Aortic outflow obstruction in the presence of an intact ventricular septum can be associated with a diminutive left ventricle and is then referred to as hypoplastic left heart syndrome (HLHS). In this anomaly, a left ventricle of inadequate size dictates management toward the strategy of staged palliation for single ventricle reconstruction, culminating in a Fontan procedure. In contrast, aortic outflow obstruction with valvular aortic stenosis (AS), an intact ventricular septum, and a normal or dilated left ventricle usually represents critical aortic valve disease. In this anomaly, balloon aortic valvuloplasty (BAV) or aortic valve surgery to relieve outflow obstruction is performed in an attempt to recruit the left ventricle as the systemic ventricle. Fetal echocardiography can accurately diagnose and distinguish between different forms of critical left-sided congenital heart disease in utero, which allows for

\footnotetext{
From the Divisions of Cardiology a and Cardiothoracic Surgery, ${ }^{\mathrm{b}}$ Children's Hospital of Philadelphia, Philadelphia, Pa.

Disclosures: Authors have nothing to disclose with regard to commercial support. Received for publication Dec 23, 2010; revisions received March 28, 2011; accepted for publication June 6, 2011; available ahead of print July 13, 2011.

Address for reprints: Jack Rychik, MD, Cardiac Center at The Children's Hospital of Philadelphia, 34th St and Civic Center Blvd, Philadelphia, PA 19104 (E-mail: Rychik@email.chop.edu).

$0022-5223 / \$ 36.00$

Copyright (C) 2011 by The American Association for Thoracic Surgery doi:10.1016/j.jtcvs.2011.06.002
}

proper prenatal counseling and preparation for specific postnatal management strategies.

We describe a distinct form of critical left-sided heart disease that does not easily fall into the categories described herein. In this anomaly, there is severe aortic outflow obstruction and an intact ventricular septum, but a normalsized or dilated left ventricle in the presence of severe mitral regurgitation (MR). The left atrium is enlarged and the atrial septum is either severely restrictive or intact. Inasmuch as mitral valve disease with significant MR is a distinctive feature, we refer to this entity as the "mitral valve dysplasia syndrome" (MVDS). This anomaly differs from other forms of critical left-sided heart disease, having discrete pathophysiologic features and a distinct set of findings discernible on fetal echocardiography. Patients with a prenatal diagnosis of the aforementioned constellation of anatomic abnormalities have previously been reported to have an extremely poor prognosis, some dying in utero. ${ }^{1-3}$ Management of MVDS as either a form of isolated critical AS or conventional HLHS can lead to decisions that lack full consideration of the uniqueness and complexity of this disease.

We report our experience with prenatally diagnosed MVDS, including prenatal progression of disease, management strategies applied, and their variable outcomes. We aim to identify prenatal echocardiographic features of MVDS that are predictive of postnatal outcomes and may guide future management decisions for these patients. By 


$$
\begin{aligned}
& \text { Abbreviations and Acronyms } \\
& \begin{aligned}
\text { AS } & =\text { aortic stenosis } \\
\text { BAV } & =\text { balloon aortic valvuloplasty } \\
\text { HLHS } & =\text { hypoplastic left heart syndrome } \\
\text { MR } & =\text { mitral regurgitation } \\
\text { MVDS } & =\text { mitral valve dysplasia syndrome } \\
\text { OHT } & =\text { orthotopic heart transplant }
\end{aligned}
\end{aligned}
$$

recognizing this constellation of cardiovascular findings as a distinct disease entity, we can devise novel strategies to improve outcomes for this patient population.

\section{METHODS \\ Patients}

Retrospective review of The Fetal Heart Program database at the Children's Hospital of Philadelphia identified fetuses with a diagnosis of MVDS syndrome between January 2002 and December 2009. Inclusion criteria were presence of a normal or dilated left ventricle in the face of aortic hypoplasia (aortic annulus diameter $<2$ standard deviations for gestational age) and hemodynamically significant MR (moderate or greater) determined by original report and confirmed by our review. All had at least 1 prenatal echocardiogram and documentation of subsequent clinical course. The study was approved by the Institutional Review Board at The Children's Hospital of Philadelphia (CHOP IRB\# 10-007559).

\section{Fetal Echocardiography}

Fetal echocardiograms were performed using a Siemens Sequoia system (Siemens Medical Solutions, Inc, Mountain View, Calif) using curvilinear 6-MHz probe. Standard imaging was performed using the American Society of Echocardiography protocol. ${ }^{4}$ Digital images were acquired as 3 -second loops and reviewed with measurements made blinded to clinical outcome using a syngo Dynamics version 8.0 (Siemens Medical Solutions, Inc) analysis workstation. An optimal 4-chamber view was identified and the cardiothoracic area ratio was measured. Right atrial, left atrial, right ventricular, and left ventricular cavity areas were individually traced at end-diastole. The sum of the left atrial and left ventricular area was compared with that of the right atrial and right ventricular area and an index of the ratio of left-sided/right-sided area was calculated as a measure of overall relative left-sided enlargement. The atrial septum was inspected with 2-dimensional imaging and interrogated with color Doppler flow mapping in multiple planes with notation made of the presence or absence of a defect. Spectral tracings of pulsed-wave Doppler interrogation of the pulmonary veins were analyzed, and patterns of flow were identified.

\section{Prenatal and Neonatal Clinical Course}

All diagnoses were confirmed, when possible, by a complete postnatal echocardiographic evaluation. In 2 patients, the left ventricular area was obtained by tracing the left ventricular cavity in end-diastole, both before and after initial palliative surgery. Charts were reviewed to obtain data concerning prenatal and neonatal clinical course. When applicable, pathology reports were reviewed and the heart specimens were examined in conjunction with a cardiac pathologist (P.W.).

\section{Data Analysis}

Echocardiographic data of left-sided/right-sided area ratio and pulmonary venous flow patterns were correlated with need for immediate postnatal intervention and outcome. Cardiac nonsurvival was defined as not alive or receiving a heart transplant. Progressive change in echocardiographic parameters from initial diagnostic fetal echocardiogram until last prenatal assessment was noted.

\section{RESULTS \\ Subjects}

Ten patients received a prenatal diagnosis of MVDS between 2002 and 2010. Data are summarized in Table 1. One family opted for nonintervention at birth (patient 9) and 9 patients were followed serially. Forty-two fetal echocardiograms were performed (range, 1-9 per fetus). Gestational age at initial diagnosis ranged from 21 to 35.7 weeks. Mean gestational age at last fetal echocardiogram was 34 \pm 4.3 weeks. Three of the 10 gestations were twin. Three patients had hydrops fetalis: 1 (patient 1 ) had spontaneous resolution of hydrops without intervention, another (patient 8 ) had stabilization of hydrops on initiation of maternal oral digoxin, and the third (patient 10) died at 29 weeks during fetal intervention. Gestational age at delivery ranged from 33.7 to 39 weeks; birth weight ranged from 1600 to $3300 \mathrm{~g}$.

\section{Echocardiographic Findings}

Echocardiographic data are reported (Table 1) from the last fetal echocardiogram in 9 patients (incomplete images in patient 6) performed at a range of 24.9 to 39 weeks of gestation.

Heart size. Six of the 9 patients had cardiomegaly noted on fetal echocardiogram with cardiothoracic area ratios greater than 0.33 (Figure 1). Left heart/right heart area ratio was predictive of cardiac mortality; no patient with a left heart/right heart area ratio of more than 1.5 at final assessment had cardiac survival beyond the neonatal period. Figure 2 demonstrates the change in left heart/right heart area ratio during gestation. Patient 1 had a ratio of 2.9 at initial presentation at 27.7 weeks of gestation and had a steady decline to 0.99 at 39 weeks, surviving beyond the neonatal period.

Atrial septum. One patient (no. 10) had an intact atrial septum and the remainder had a restrictive atrial septum on initial fetal echocardiogram. Three patients progressed from a restrictive atrial septum on fetal echocardiogram to an intact atrial septum at birth. Patient 7 had an intact atrial septum on the final fetal echocardiogram at 34 weeks. The remaining 2 patients had a restrictive atrial septum on the final fetal echocardiogram but an intact atrial septum on the initial postnatal echocardiogram. All patients with an intact atrial septum at birth had a left heart/right heart ratio of 1.5 or more on fetal echocardiogram.

Pulmonary venous Doppler flow patterns. Two patients had normal pulmonary venous Doppler patterns (Figure 3, $A$ ). Four patients had blunting of peak velocity of the systolic wave and significant atrial systolic flow reversal (Figure 3,B), a pattern similar to that previously described 
TABLE 1. Data on 10 patients with a prenatal diagnosis of MVDS between 2002 and 2009

\begin{tabular}{|c|c|c|c|c|c|c|c|c|c|c|}
\hline & $\begin{array}{c}\text { Patient } \\
1\end{array}$ & $\begin{array}{c}\text { Patient } \\
2\end{array}$ & $\begin{array}{c}\text { Patient } \\
3\end{array}$ & $\begin{array}{c}\text { Patient } \\
4\end{array}$ & $\begin{array}{c}\text { Patient } \\
5\end{array}$ & $\begin{array}{c}\text { Patient } \\
6\end{array}$ & $\begin{array}{c}\text { Patient } \\
7\end{array}$ & $\begin{array}{c}\text { Patient } \\
8\end{array}$ & $\begin{array}{l}\text { Patient } \\
9\end{array}$ & $\begin{array}{c}\text { Patient } \\
10\end{array}$ \\
\hline $\begin{array}{l}\text { GA at initial } \\
\quad \text { diagnosis (wk) }\end{array}$ & 27.7 & 28 & 21 & 21 & 23.3 & 35.7 & 32 & 30.7 & 24.9 & 28 \\
\hline Fetal echoes (n) & 4 & 4 & 4 & 9 & 6 & 1 & 3 & 6 & 1 & 4 \\
\hline $\begin{array}{c}\text { GA at last fetal } \\
\text { echo (wk) }\end{array}$ & 39 & 37 & 35 & 36 & 38 & 35.7 & 34 & 33 & 24.9 & 29.3 \\
\hline Twin gestation & No & Yes & No & No & No & No & Yes & No & Yes & No \\
\hline Hydrops & Yes & No & No & No & No & No & No & Yes & No & Yes \\
\hline $\begin{array}{l}\text { Left/right heart } \\
\text { area ratio }\end{array}$ & 0.99 & 0.77 & 1.1 & 1.82 & 0.54 & NA & 2.3 & 2.73 & 1.52 & 2.05 \\
\hline $\begin{array}{l}\text { PV Doppler } \\
\text { flow pattern }\end{array}$ & Normal & Normal & $\begin{array}{l}\text { Atrial } \\
\quad \text { reversal }\end{array}$ & $\begin{array}{l}\text { Atrial } \\
\quad \text { reversal }\end{array}$ & $\begin{array}{l}\text { Atrial } \\
\quad \text { reversal }\end{array}$ & NA & $\begin{array}{l}\text { Double } \\
\text { reversal }\end{array}$ & $\begin{array}{l}\text { Double } \\
\text { reversal }\end{array}$ & $\begin{array}{l}\text { Atrial } \\
\quad \text { reversal }\end{array}$ & $\begin{array}{l}\text { Double } \\
\text { reversal }\end{array}$ \\
\hline $\begin{array}{l}\text { Fetal } \\
\quad \text { intervention }\end{array}$ & None & None & BAV & $\begin{array}{l}\text { BAV, } \\
\text { digoxin }\end{array}$ & None & None & None & Digoxin & None & BAS \\
\hline $\begin{array}{l}\text { GA at delivery } \\
\text { (wk) }\end{array}$ & 39 & 37.4 & 38.6 & 38.1 & 37.9 & 36 & 34.7 & 33.7 & 37 & $\begin{array}{l}\text { Fetal } \\
\text { death }\end{array}$ \\
\hline $\begin{array}{l}\text { Atrial septal } \\
\text { status at birth }\end{array}$ & Restrictive & Restrictive & Restrictive & Intact & Restrictive & Restrictive & Intact & Intact & Unknown & NA \\
\hline $\begin{array}{l}\text { Immediate } \\
\text { postnatal } \\
\text { intervention }\end{array}$ & None & None & None & Atrial stent & Atrial stent & $\begin{array}{l}\text { Atrial } \\
\text { septectomy }\end{array}$ & $\begin{array}{l}\text { Attempted } \\
\text { atrial stent }\end{array}$ & $\begin{array}{l}\text { Atrial } \\
\text { stent }\end{array}$ & None & NA \\
\hline $\begin{array}{l}\text { Postnatal } \\
\text { operative } \\
\text { strategy }\end{array}$ & Norwood & Norwood & OHT & OHT & Norwood & Norwood & NA & Hybrid & $\begin{array}{l}\text { Palliative } \\
\text { care }\end{array}$ & NA \\
\hline $\begin{array}{l}\text { Age at } \\
\text { operation (d) }\end{array}$ & 8 & 2 & 36 & 36 & 3 & 0 & 0 & 7,16 & NA & NA \\
\hline $\begin{array}{c}\text { Survival to } \\
\text { hospital } \\
\text { discharge }\end{array}$ & Yes & Yes & No & Yes & Yes & Yes & No & No & NA & NA \\
\hline $\begin{array}{l}\text { Status at } \\
\text { publication } \\
\text { (surgical } \\
\text { stage) }\end{array}$ & $\begin{array}{l}\text { Alive } \\
\text { (Fontan) }\end{array}$ & $\begin{array}{l}\text { Alive } \\
\qquad \text { (BDG) }\end{array}$ & Dead & $\begin{array}{l}\text { Alive } \\
\qquad(\mathrm{s} / \mathrm{p} \text { OHT })\end{array}$ & $\begin{array}{l}\text { Alive } \\
\text { (BDG) }\end{array}$ & $\begin{array}{l}\text { Alive } \\
\qquad \text { (Fontan) }\end{array}$ & Dead & Dead & Dead & Dead \\
\hline
\end{tabular}

in fetuses with HLHS and a severely restrictive or intact atrial septum..$^{5-7}$ In 3 patients, there was a unique pulmonary venous Doppler pattern with 2 distinct waves of flow reversal per cardiac cycle; 1 in atrial systole and 1 in ventricular systole (Figure 3,C). In this group, all patients had a severely dilated left atrium with a left heart/right heart area ratio greater than 2 and had the greatest degree of MR. Of these 3 patients, 1 patient (no. 10) underwent fetal intervention and died. The other patients (nos. 7 and 8 ) received urgent postnatal intervention on the atrial septum owing to 


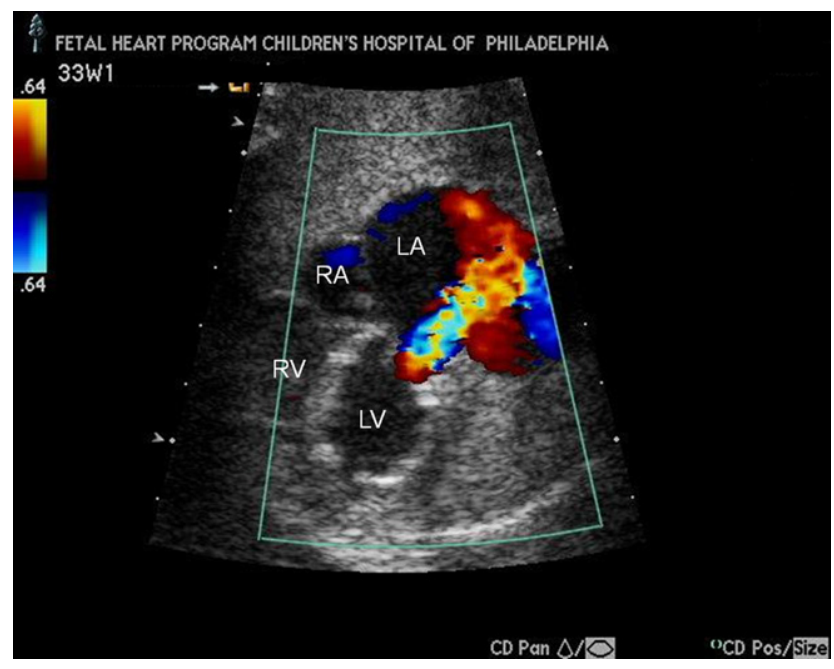

FIGURE 1. Fetal ultrasound at 34 weeks in a patient with MVDS and a severely dilated left atrium $(L A)$ and left ventricle $(L V)$ compared with a much smaller right atrium $(R A)$ and right ventricle $(R V)$. Color Doppler over the mitral valve shows severe mitral regurgitation, typical in this patient population.

severe hypoxemia. Pulmonary venous Doppler flow patterns correlated with outcome, inasmuch as both fetuses with normal flow and 2 of 4 with isolated atrial systolic wave reversal are alive. None of the patients with the "double flow reversal" pattern are alive.

With regard to progression of pulmonary venous Doppler patterns, all except patient 7 had unchanged pulmonary venous Doppler patterns from point of initial diagnosis to the final fetal echocardiogram. Patient 7 had progression from isolated atrial flow reversal to the "double flow reversal" pattern at 34 weeks of gestation. This patient also had progression from a restrictive atrial septum at the time of initial

Left Heart to Right Heart Area Ratio

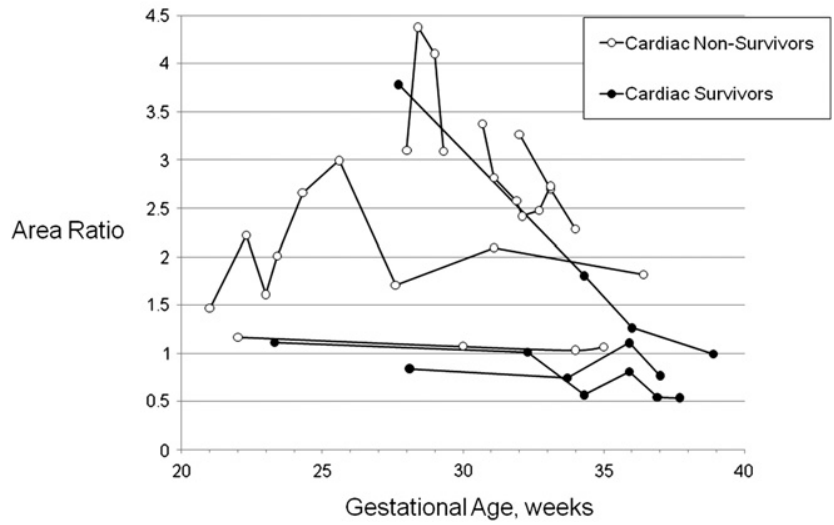

FIGURE 2. Ratio of left heart to right heart area for each patient echo by gestational age. Each circle represents a single fetal echocardiogram at the corresponding gestational age. Patients living with their native hearts are represented by closed black circles. Patients who died or underwent heart transplant are marked by open circles.

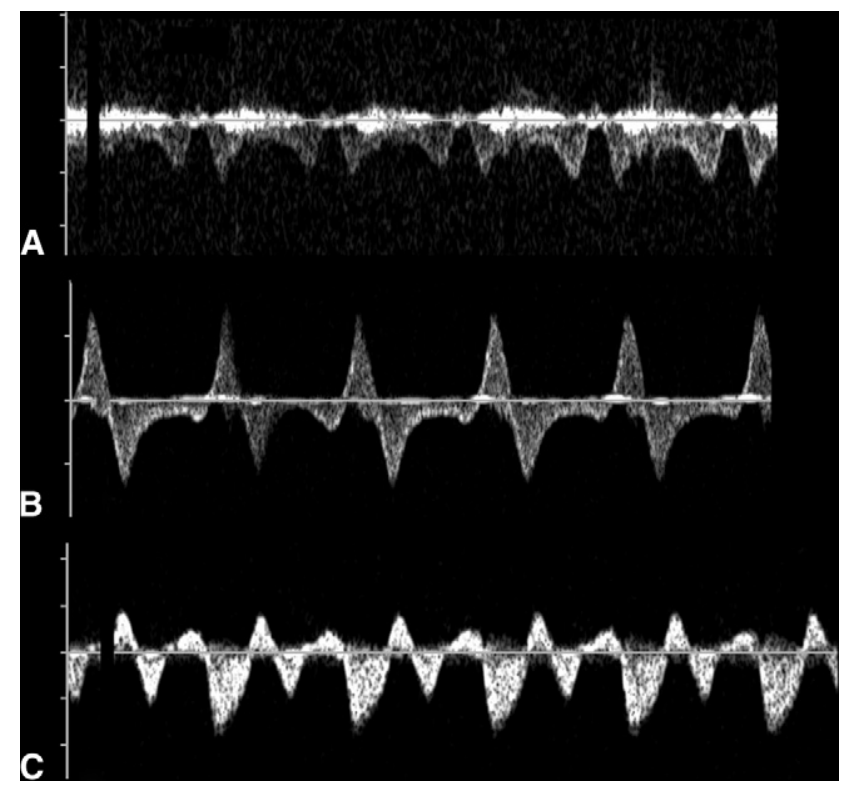

FIGURE 3. A, Normal pulmonary venous Doppler pattern. B, Pulmonary venous Doppler pattern with retrograde flow during atrial systole. C, Pulmonary venous Doppler pattern of a patient with severe mitral regurgitation and restrictive atrial septum. There is flow reversal in both atrial and ventricular systole, giving a "double reversal" pattern.

diagnosis to an intact atrial septum during the same time course.

\section{Fetal Intervention, Postnatal Course, and Outcomes}

Fetal intervention. Three fetuses underwent prenatal cardiac intervention. Two had in utero BAV in an attempt to promote forward flow and decompress the left ventricle (patient 3 operated on at our center and patient 4 at another institution). Technical success was achieved in opening the aortic valve and generating antegrade flow into the transverse aorta; however, aortic insufficiency ensued and both fetuses continued to exhibit severe left ventricular dilation and dysfunction. Fetal intervention on the aortic valve did not improve the degree of MR in either patient; MR worsened in patient 4 as gestation progressed.

One patient (no. 10) underwent in utero balloon atrial septostomy. Through maternal laparotomy, a 19-gauge needle was introduced across the uterine wall into the fetal chest and positioned in the fetal heart. Despite multiple attempts, an adequate-sized interatrial communication was not satisfactorily created. With the third attempt, a left ventricular thrombus developed with subsequent bradycardia and fetal death.

Postnatal management. Postnatal echocardiograms (patients 1-8) confirmed the diagnosis of MVDS. The status of the atrial septum is reported in Table 1. All patients had dysplastic, regurgitant mitral valves.

Five patients had a highly restrictive or intact atrial septum accompanied by severe hypoxemia and hypercarbia 
requiring an immediate postnatal intervention to open the atrial septum. Three of these patients were born by cesarean section in the cardiac operating room and taken directly for intervention after initial stabilization and brief echocardiographic evaluation. One patient, born at an outside hospital, was transported directly to the cardiac catheterization laboraory for intervention. One patient was transferred from an outside hospital, evaluated in our cardiac intensive care unit, and taken to the operating room on the day of birth for a Norwood procedure, including atrial septectomy.

A total of 4 patients had an urgent intervention in the cardiac catheterization laboratory. Three had atrial septal stent placement with successful decompression of the left atrium; 1 patient (no. 7) died in the cardiac catheterization laboratory secondary to cardiac puncture and development of hemopericardium.

Surgical palliation. Four patients underwent the Norwood procedure with a modified Blalock-Taussig shunt. So that the left ventricle would be excluded, 2 patients (nos. 1 and 2) had simultaneous suture closure of the mitral valve at the time of the Norwood operation. Both had a dramatic change in ventricular geometry after the procedure, with a $79 \%$ decrease in left ventricular cavity area from $27 \mathrm{~cm}^{2} / \mathrm{m}^{2}$ to $5.7 \mathrm{~cm}^{2} / \mathrm{m}^{2}$ in (patient 1 ), and a $68 \%$ decrease in left ventricular cavity area from $10 \mathrm{~cm}^{2} / \mathrm{m}^{2}$ to $3.2 \mathrm{~cm}^{2} / \mathrm{m}^{2}$ in patient 2 . All 4 patients who underwent the Norwood operation survived and have continued with staged reconstructive surgery ( 2 bidirectional Glenn and 2 bidirectional Glenn followed by Fontan operation) without evidence of significant pulmonary vascular disease. Patient 8 , with prematurity and low birth weight, underwent a staged "hybrid procedure" with placement of an atrial stent at birth, followed by placement of bilateral pulmonary artery bands at 1 week and stent placement in the ductus arteriosus at 2 weeks of age. However, progressive right ventricular dysfunction developed, and the patient died at 2 months of age.

Owing to persistent severe MR, severe left ventricular dysfunction, and secondary right ventricular dysfunction, 2 patients were listed for orthotopic heart transplant (OHT). OHT was performed in both infants 4 weeks after birth; 1 patient died 57 days after birth secondary to sepsis after $\mathrm{OHT}$ and the other is currently alive.

Of the 10 initial fetuses, $5(50 \%)$ are currently alive, 4 after cavopulmonary surgery and 1 after OHT. Of the 5 deaths, 1 occurred during fetal atrial septoplasty, 1 after nonintervention at birth, 1 of complications during catheter-based intervention, 1 after a "hybrid procedure," and 1 after OHT.

\section{Autopsy and Pathologic Findings}

Five patients had cardiac autopsy; 2 explanted hearts, 2 after death in the newborn period, and 1 after death during fetal intervention. The hearts were at least twice the weight expected for age. All had AS with the common finding of a unicuspid aortic valve and hypoplasia of the ascending aorta. Aortic valve diameter size measured $4 \mathrm{~mm}$ in the 2 patients who had undergone fetal BAV and ranged from 0.5 to $2 \mathrm{~mm}$ in the others. In all 5 specimens, the left ventricles were dilated with endocardial fibroelastosis and the left atria were dilated with abnormally thickened walls, consistent with left atrial hypertension. All 5 specimens had mitral stenosis with deficient valve chordae and mitral valve leaflet attachment directly onto the papillary muscles, an "arcadetype" mitral valve with thickened, dysplastic valve leaflets (Figure 4). ${ }^{8}$

\section{DISCUSSION}

MVDS is a congenital heart anomaly defined by aortic valve stenosis, mitral valve arcade with thickened and dysplastic leaflets, significant mitral insufficiency, left heart dilation, and marked restriction of the atrial septum. This unusual constellation of findings is distinct from critical AS and HLHS. In our series, cardiac mortality is more than $50 \%$, higher than that reported in HLHS with a highly restrictive or intact atrial septum. ${ }^{9,10}$ We have identified fetal echocardiographic characteristics that predict mortality and unstable transition at birth. These findings provide critical guidance for counseling families, selecting candidates for fetal intervention, and preparing for delivery of critically ill infants with this rare heart defect.

Several measureable parameters were predictive of the need for immediate postnatal intervention and overall cardiac mortality in our series. Fetuses with a larger left heart/right heart area ratio had a higher risk of overall cardiac mortality. In fact, all patients with a ratio

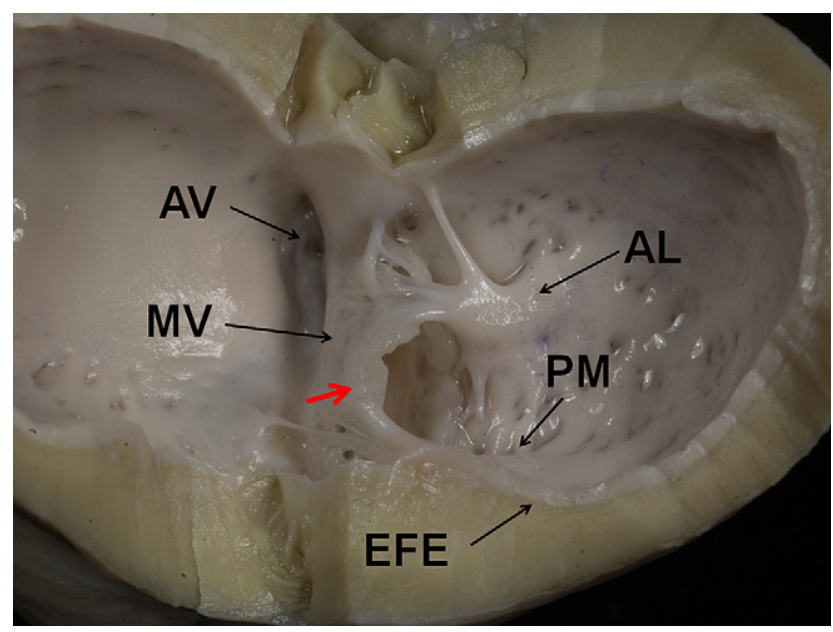

FIGURE 4. Photograph of specimen with MVDS. The mitral valve $(M V)$ appears dysplastic with thickened leaflets that connect, via a fibrous ridge (red arrow) directly to the anterior lateral $(A L)$ and posterior medial $(P M)$ papillary muscles. Severe aortic valve $(A V)$ hypoplasia is seen. Endocardial fibroelastosis $(E F E)$ is seen lining the entire left ventricle. 
greater than 1.5 at final fetal echocardiogram died in the neonatal period. In addition, patients born with an intact atrial septum, compared with a restrictive septum, tended to have a higher left heart/right heart area ratio in fetal life, inasmuch as decompression of the left-sided blood volume is further impaired in those with an intact atrial septum.

We identified a unique pulmonary venous Doppler pattern, a double flow reversal pattern, predictive of the need for immediate postnatal intervention. In this Doppler pattern, the first wave of reversal occurs during ventricular systole and likely signifies the effect of MR on a tense, blood-filled pulmonary vein. The second wave of reversal is associated with atrial contraction. This pattern is likely found in patients with the greatest degree of MR, largest left atrial and left ventricular volumes, and highest left atrial pressures - the most severe spectrum of this disease. Both fetuses who survived to delivery with this double reversal flow pattern required an immediate postnatal intervention to alleviate left atrial hypertension; however, neither patient survived the neonatal period.

In contrast, the 2 fetuses with completely normal pulmonary vein Doppler patterns did not need an immediate postnatal intervention and both are current survivors. Therefore, the presence of a normal pulmonary venous Doppler pattern in utero may be reassuring, representing a subset of patients who tolerate the transition to extrauterine life without great difficulty and ultimately become candidates for single ventricle palliation.

Fetal intervention by BAV did not benefit the 2 patients in our cohort who underwent this procedure. Intervention on the aortic valve was undertaken on the basis of existing data that in utero BAV in the fetus with AS and a wellformed left ventricle may successfully halt the progression of evolving HLHS. ${ }^{11}$ In addition, we hypothesized that opening the aortic valve might decompress the left ventricle and reduce the degree of mitral insufficiency. ${ }^{12}$ Despite technical success in both fetuses, neither exhibited improved left ventricular function, a decrease in left ventricular dilation, or a reduction in the degree of mitral insufficiency. Both patients were born with left ventricles that were unable to support systemic circulation in the setting of iatrogenic severe aortic insufficiency.

This experience suggests that BAV may not be the correct strategy for this population, inasmuch as the principal disorder is not aortic valve disease but rather a structurally abnormal and regurgitant mitral valve. In fetal life, we believe that the insufficient mitral valve causes left atrial hypertension, which alters atrial septal morphology by causing adherence of septum primum to septum secundum, ultimately causing atrial septal restriction. ${ }^{13}$ Impediment to left atrial egress with MR increases left atrial volume, promoting mitral annular dilatation and abnormal leaflet coaptation, further worsening MR in a progressive manner.
Aortic outflow obstruction compounds this picture by disallowing adequate forward flow through the left ventricle, contributing to left ventricular dilation. The resultant left heart dilation likely leads to compression of the right side to a critical degree, impairing cardiac output. In some fetuses this can result in hydrops.

This primary mitral valve abnormality results in a left heart incapable of supporting systemic circulation. Therefore, despite the seductive appearance of a large left ventricle, these patients are best managed with a single ventricle palliative strategy. In this setting, creation of aortic insufficiency will have negative consequences, including compromising coronary perfusion and increasing the volume load on an already dilated left ventricle, potentially further impairing right ventricular mechanics.

Despite our experience with fetal BAV, the opportunity to alter a disease with such high neonatal mortality may still lie with fetal intervention. Postnatally, our current strategy involves opening of the atrial septum, alleviating left atrial hypertension, and allowing decompression of the entire left heart. We have witnessed a reduction in degree of MR and a dramatic decompression of the left atrium and left ventricle after adequate opening of the atrial septum in these patients.

Relief of atrial septal restriction in the fetus by balloon atrial septostomy has been described in patients with HLHS and a highly restrictive or intact atrial septum. ${ }^{14}$ In the fetus with MVDS, this procedure has several potential benefits. Left atrial decompression may alter mitral annular forces and reduce MR, while left ventricular decompression will decrease the negative impact of a large, dysfunctional left ventricle on right ventricular mechanics. Thus, right ventricular filling and systolic performance will improve, leading to increased fetal cardiac output. In addition, prenatal relief of left atrial hypertension may promote more normal fetal lung development. Although our attempt at adequately opening the atrial septum in 1 hydropic fetus was unsuccessful, continued efforts toward improving the technical aspects of the procedure are worthwhile. We have identified an extremely high-risk group of fetuses with MVDS. Therefore, continued experimentation with various balloon atrial septostomy techniques may be warranted for the fetus with MVDS with a left heart/right heart ratio of more than 1.5 or double reversal pattern on Doppler interrogation of the pulmonary veins.

Finally, it is worth noting that 2 patients who did not have an immediate postnatal intervention and proceeded directly to a Norwood procedure with suture closure of the mitral valve experienced significant left ventricular decompression postoperatively. This decrease in left ventricular size likely resulted from a combination of atrial septectomy and exclusion of the left ventricle by oversewing of the mitral valve. Therefore, suture closure of the mitral valve should be considered to maximize left 
ventricular decompression, thereby improving right ventricular efficiency.

In summary, MVDS is a unique form of critical left-sided heart disease with a high neonatal mortality. Fetal diagnosis and serial fetal echocardiographic follow-up may provide information about overall mortality risk and identify patients who need immediate postnatal intervention. In addition, further studies are needed to determine whether in utero relief of atrial septal restriction can alter disease severity and improve outcomes in patients identified to be at highest risk for mortality.

\section{References}

1. Bharati S, Patel A, Varga P, Husain AN, Lev M. In utero echocardiographic diagnosis of premature closure of the formen ovale with mitral regurgitation and large left atrium. Am Heart J. 1991;122:597-600.

2. Nowlen TT, Ayres NA, Kearney DL, Nihill MR, Grifka RG. Premature closure of the foramen ovale associated with aortic stenosis, left ventricular dilation with thrombus and early mortality. Am J Cardiol. 2000;85:1159-61.

3. Vogel M, McElhinney DB, Wilkins-Haug LE, Marshall AC, Benson CB, Juraszek AL, et al. Aortic stenosis and severe mitral regurgitation in the fetus resulting in giant left atrium and hydrops. J Am Coll Cardiol. 2011;57:348-55.

4. Rychik J, Ayres N, Cuneo B, Gotteiner N, Hornberger L, Spevak P, et al. American Society of Echocardiography guidelines and standards for performance of the fetal echocardiogram. J Am Soc Echocardiogr. 2004;17:803-10.
5. Taketazu M, Barrea C, Smallhorn J, Wilson GJ, Hornberger LK. Intrauterine pulmonary venous flow and restrictive foramen ovale in fetal hypoplastic left heart syndrome. J Am Coll Cardiol. 2004;43:1902-7.

6. Chintala K, Tian Z, Du W, Donaghue D, Rychik J. Fetal pulmonary venous Doppler patterns in hypoplastic left heart syndrome: relationship to atrial septal restriction. Heart. 2008;94:1374-5.

7. Better DJ, Apfel HD, Zidere V, Allan LD. Pattern of pulmonary venous blood flow in the hypoplastic left heart syndrome in the fetus. Heart. 1999;81:646-9.

8. Layman TE, Edwards JE. Anomalous mitral arcade: a type of congenital mitral insufficiency. Circulation. 1967;35:389-95.

9. Vida VL, Bacha EA, Larrazabal A, Gauvreau K, Thiagaragan R, FynnThompson F, et al. Hypoplastic left heart syndrome with intact or highly restrictive atrial septum: surgical experience from a single center. Ann Thorac Surg. 2007;84:581-6.

10. Glatz JA, Tabbutt S, Gaynor JW, Rome JJ, Montenegro L, Spray TL, et al. Hy poplastic left heart syndrome with atrial level restriction in the era of prenatal diagnosis. Ann Thorac Surg. 2007;84:1633-8.

11. McElhinney DB, Marshall AC, Wilkins-Haug LE, Brown DW, Benson CB, Silva V, et al. Predictors of technical success and postnatal biventricular outcome after in utero aortic valvuloplasty for aortic stenosis with evolving hypoplastic left heart syndrome. Circulation. 2009;120:1482-90.

12. Selamet Tierney ES, Wald RM, McElhinney DB, Marshall AC, Benson CB, Colan SD, et al. Changes in left heart hemodynamics after technically successful in-utero aortic valvuloplasty. Ultrasound Obstet Gynecol. 2007;30:715-20.

13. Rychik J, Rome JJ, Collins MH, Decampli WM, Spray TL. The hypoplastic left heart syndrome with intact atrial septum: atrial morphology, pulmonary vascular histopathology and outcome. J Am Coll Cardiol. 1999;34:554-60.

14. Marshall AC, Levine J, Morash D, Silva V, Lock JE, Benson CB, et al. Results of in utero atrial septoplasty in fetuses with hypoplastic left heart syndrome. Prenat Diagn. 2008;28:1023-8. 